\title{
Aréstegui, N. (2020). El padre Horán. Estudio preliminar de Mercedes Mayna y edición crítica de César Coca. Lima: Ediciones MYL.
}

Dentro del amplio espectro de los estudios literarios peruanos, el trabajo de archivo revela importantes hallazgos que requieren investigadores que puedan aprehender la multiplicidad de sus sentidos. Así pues, por ejemplo, en los últimos años hemos visto el rescate de las obras de Gamaliel Churata y su revista Boletín Titikaka, lo que derivó en el incremento de los estudios a escala internacional. Sin embargo, esta labor no es atendida en la medida necesaria por nuestra comunidad académica, por lo que la crítica tiende a trabajar con los materiales ya dados, y que han destacado aún a pesar del paso del tiempo, o con objetos de estudio incompletos o alterados a los que se presentaron inicialmente.

Sobre esto último, conviene referirnos más por ser el motivo central de nuestro comentario. Es común encontrar segundas o terceras ediciones de libros peruanos, sobre todo de nuestros clásicos. No obstante, también notamos que, con frecuencia, presentan alteraciones con respecto a la primera y que escapan de la voluntad del autor, generalmente alterados por criterios mercantiles o extraliterarios. Ante ello, la ecdótica como disciplina literaria propone, según Ana Díaz Alejo en su Manual de edición crítica de textos literarios (2003), depurar al texto "de toda contaminación gráfica espacial y temporal, y restituirle su original apariencia". La aparición de un proyecto sistemático de ediciones críticas viene a poner un orden en nuestra tradición literaria al fijar un texto a través de una "historia de las ediciones" y presentar un estudio preliminar elaborado por un académico especializado que permita al lector, que se acerca por primera vez a un libro de tal época o género, manejar una serie de códigos o lecturas que faciliten la comprensión o análisis del mismo.

Ediciones MYL hace su aparición dentro de la comunidad académica con su "Colección Literaria Ediciones Críticas", que suple en el país lo que, entre otros ejemplos, el Estado boliviano realiza con su Biblioteca del Bicentenario. Karen Huachaca Avendaño dirige el proyecto editorial conformado por catorce colecciones, donde la primera, "Colección siglo XIX (Novelas de folletín)", se inaugura con El padre Horán de Narciso Aréstegui. Esta propuesta nace, además, con la finalidad de completar los proyectos que se realizaron por los 100 y 150 años de vida republicana. Con este proyecto revive el interés por construir, o reivindicar, una tradición literaria nacional impulsada por las celebraciones del Bicentenario. Así, MYL está construyendo un canon de clásicos y obras relegadas que, a la luz de las nuevas investigaciones, encuentran una oportunidad de tener el estatus que se les había arrebatado. Es, entonces, una estrategia de doble propuesta: por un lado, impone una selección desde un criterio valorativo propio y, por otro, solicita una atención crítica hacia esta por parte de los estudiosos de la Literatura.

Para esta edición de más de 700 páginas, el estudio introductorio fue desarrollado por Mercedes $\mathrm{Ma}$ yna Medrano (University of Pennsylvania). El principal cuestionamiento para adentrarse en el universo de la ficción del autor radica en encontrar cuál es la vigencia de una obra del XIX dos siglos después, en un mundo en que "la pasión obsesiva masculina, así como mujeres no creyendo en mujeres, es una experiencia común". Sin embargo, este interés no se agota solo en el carácter temático de la obra, sino también en su importancia histórica al ser considerada por gran parte de la crítica como una de las primeras novelas peruanas y en su acercamiento a la problemática de la situación indígena. Para tal fin, realiza antes una investigación biobibliográfica sobre Narciso Aréstegui y un recuento crítico sobre la recepción histórica de la novela por parte de los estudiosos, desde Ricardo Palma hasta James Higgins. En este punto, Mayna presenta un balance de la cuestión, resaltando las ideas más importantes de los críticos sobre la novela. Si bien al inicio menciona que la crítica, en muchos casos, la acusaron de excesos melodramáticos, este apartado, debido a su carácter cronológico, resulta muy esquemático, pues no llega a ninguna conclusión más allá de la mencionada y no permite establecer un diálogo entre las propuestas individuales. Sin embargo, destacamos el hecho de discrepar de determinadas ideas y adoptar una postura contraria, como sucede con la de Edmundo Bendezú.

Posteriormente, incidirá en el género folletinesco y su relación con el melodrama en El padre Horán. Aquí, Mayna Medrano resaltará las características del folletín como un medio de alcance masivo que facilita la difusión de una doctrina liberal y modernizadora, como la de Aréstegui, a través de la ficción; y que, además, se vale del melodrama como una herramienta que enfatiza en una disputa y distinción clara entre el bien y el mal para ofrecer al lector "una manera de moralizar y ordenar un mundo que había perdido sus bases éticas conocidas". Esta operación se observará más detalladamente a través de las relaciones amorosas desarrolladas, como la de Angélica y Horán o Doloritas y Wenceslao, y mediante las estratégicas posiciones económicas que los personajes plantean en sus diálogos.

El trabajo de fijación del texto y notas es realizado por César Coca (The City University of New York) a partir de una "historia de las ediciones". De esta manera, basándose en la del folletín y la primera publicada en seis tomos, propone "un texto acorde con los criterios 
actuales de fijación de textos decimonónicos". Además de una actualización ortográfica, el valor que añade esta edición es el de incluir los párrafos del capítulo XII que las posteriores ediciones omitían. Esta labor permite fijar un texto único que se había desvirtuado incluso desde su primera reedición; así, la comunidad académica encuentra aquí una novela fijada con la cual trabajar y que se ciñe con mayor fidelidad a la ideada por Aréstegui en un primer momento.
El proyecto que se propone Ediciones MYL rumbo al Bicentenario, cuyas celebraciones oficiales culminan en el año 2024, es muy ambicioso, pero sobre todo útil por su validez para un circuito académico que ha hecho caso omiso, desde su área profesional, al trabajo y cuidado de las ediciones críticas. Este equipo de investigadores jóvenes está construyendo una base sólida que sostendrá todo el aparato crítico de nuestra literatura nacional.

\section{Alex Hurtado}

Universidad Nacional Mayor de San Marcos, Lima, Perú Contacto: alex.hurtado@unmsm.edu.pe https://orcid.org/0000-0003-2722-6635 